\title{
FREQUENCY AND PREDICTORS OF ACCESS FAILURE IN PATIENTS UNDERGOING URETERORENOSCOPY FOR UPPER URINARY TRACT CALCULI
}

\author{
Ahsan Rafi, Wajahat Aziz, Hammad Ather
}

Aga Khan University, Karachi Pakistan

\begin{abstract}
Objective: To determine the frequency and factors responsible for access failure during primary ureteroscopy (URS).

Study Design: Cross-sectional study.

Place and Duration of Study: Aga Khan University, Karachi Pakistan, from Jan to Jul 2019.

Methodology: All patients undergoing Ureterorenoscopy for upper urinary tract urolithiasis were included. Ureterorenoscopy was performed with either semi rigid, rigid digital or fiber opticflexible ureterorenoscope as appropriate. Data was collected for demographics, history of stone passage, previous Ureterorenoscopy / double J stenting and history of stent placement. Preoperative imaging reviewed for stone location, size and number. Level of access failure (proximal/mid/distal ureter) was noted. Post-operative complications and need of ancillary procedure was noted.

Results: We included 250 participants undergoing ureteroscopy for the upper urinary tract calculi. Mean age of the patients was $44.15 \pm 13.76$ years. Mean stone size was $9.12 \pm 4.23 \mathrm{~mm}$. Overall access failure rate was found to be $8 \%$ (20/250), all required an ancillary procedure. None of the patients with previous history of endoscopic intervention or stone passage had access failure. On univariate and multivariate analysis only stone location was found to be significant factor predicting access failure. Conclusion: Failure to access is not uncommon during primary ureteroscopy. Access failure is more common in proximal ureteral stone and in patients with no previous episode of ureteral stones and procedure. Information from this study will help in counseling patients' pre-operatively and may be a guide to urologists on pre-stenting of selected patients at high risk of access failure.
\end{abstract}

Keywords: Access failure, Endoscopy, FURS, RIRS, Ureteroscopy, Urolithiasis.

This is an Open Access article distributed under the terms of the Creative Commons Attribution License (https://creativecommons.org/licenses/by-nc/4.0/), which permits unrestricted use, distribution, and reproduction in any medium, provided the original work is properly cited.

\section{INTRODUCTION}

Ureterorenoscopy (URS) is one of the most common option for fragmentation and retrieval of upper urinary tract calculi. Young performed first ever URS procedure in nineteenth century with a pediatric cystoscope ${ }^{1,2}$. During initial development of ureterorenoscopes all the procedures demanded ureteral dilatation by conical dilators ${ }^{3}$. Evaluation of modern ureterorenoscopy has decreased the number of complications and frequency of access failure. With advancements in technique and instrumentation including miniaturization of scopes, and development of digital and flexible scopes any stone in urinary tract can be accessed during ureterorenoscopy and URS is now considered the gold standard for most small upper tract stones ${ }^{4}$. This improvement in technology have allowed use of URS for extended indications even in large stones e.g. in patients with percutaneous lithotripsy (PNL) failure, obesity, and musculoskeletal deformity ${ }^{5}$.

Primary ureteroscopic intervention for kidney or ureteral stones occasionally encounters difficulty in passing the scope thus requiring staged treatment or

Correspondence: Dr Ahsan Rafi, C/O Ashraf Fidai, Surgery Link Building, Aga Khan University, Karachi Pakistan

Received: 20 Nov 2019; revised received: 28 Nov 2019; accepted: 03 Dec 2019 alternative approach. Despite advancement in technique and miniaturization of instruments, occasionally failure to access upper tract with URS can happen. This results in need for additional procedure, added cost, morbidity and frustration both for patient and surgeon.

Frequency of access failure in various retrospective studies is $7.7-16 \% 6,7$. There are several factors which can lead to access failure including patient and stone related factors. Suggested factors include higher BMI, proximal stone location, younger patient and naive ureter (no history of previous endoscopic intervention) and stone passage ${ }^{5}$.

We aimed to assess the access failure rate of primary ureterorenoscopy and determine factors, which can potentially predict access failure. This will help in counselling the patients pre-operatively and can improve clinical decision for choosing appropriate modality for patients with upper ureteric and renal stones.

\section{METHODOLOGY}

After ERC approval this cross sectional prospective study was conducted at urology department of a teaching University hospital. All patients 18-70 years of age undergoing ureterorenoscopy for upper ureteric or renal stone were included. Presented patients and 
patients with active infection and with previous history of open renal/ureteric surgery were excluded. URS was performed by consultant urologists with experience of at least 50 independent ureterorenoscopy. Ureteroscopy was performed with semi rigid 6.8FR ureteroscope followed by $8 \mathrm{FR}$ semi rigid ureteroscope or 9Fr flexible ureteroscope (storz) as appropriate. Data was collected for demographics including age, gender, BMI, prior history of stone passage, previous history of ureterorenoscopy or JJ stenting and whether patient is prestented at time of this URS. Pre op imaging was reviewed for stone location size and number. Access failure was defined as unable to reach stone with any ureterorenoscope during URS. Whether access failure occurred during procedure was noted. Level of access failure (proximal/mid/distal ureter) was also noted. Post-operative complications and need of ancillary having access failure were compared with patients in which access was achieved, there was no significant difference in Age, BMI, Gender, laterality, size and number of stones. Among patients with distal or mid ureteric stones access failure rate was 2.19\% (3/137), whereas among patients with proximal ureteric or renal stones, access failure rate was $15.04 \%$ (17/113).

On univariate and multivariate analysis only stone location was found to be statistically significant predictor of access failure ( $p$-value 0.003). The site of access failure during ureteroscopy was also noted. In most of the patients with access failure, ureteroscope could not be negotiated beyond mid ureter $(14 / 20=$ $70 \%$ ). Only 2 patients had complication requiring intervention/readmission both of them with ureteric injuries one requiring insertion of double J stent and other with insertion of per cutaneous nephrostomy.

Table-I: Baseline demographics.

\begin{tabular}{|c|c|c|c|c|c|c|c|}
\hline & & & Total & Accessed & Access Failure & $\begin{array}{c}\text { Access Failure } \\
\text { Rate }(\%)\end{array}$ & $p$-value \\
\hline & & Number & $n=250$ & 230 & $n=20$ & $20 \%$ & \\
\hline \multirow{7}{*}{ Patient } & Age & Mean \pm SD & $44.15 \pm 13.76$ & $44.53 \pm 13.52$ & $39.75 \pm 15.98$ & - & 0.20 \\
\hline & BMI & Mean \pm SD & $27.12 \pm 4.52$ & $28.41 \pm 4.50$ & $27.01 \pm 4.60$ & - & 0.21 \\
\hline & \multirow{2}{*}{ Gender } & Male & 183 & 168 & 15 & 8.20 & 1 \\
\hline & & Female & 67 & 62 & 5 & 7.46 & - \\
\hline & \multirow{3}{*}{ History of } & Stone Passage & 36 & 36 & 0 & 0.00 & 0.11 \\
\hline & & Prior JJ Stenting & 16 & 14 & 2 & 12.50 & 0.83 \\
\hline & & Prior URS & 21 & 21 & 0 & 0.00 & 0.32 \\
\hline \multirow{7}{*}{ Stone } & \multirow{2}{*}{ Location } & Mid/Distal Ureter & 137 & 134 & 3 & 2.19 & 0.00 \\
\hline & & Prox Ureter/Kidney & 113 & 96 & 17 & 15.04 & - \\
\hline & Size & - & $9.12 \pm 4.23$ & $9.04 \pm 4.15$ & $9.97 \pm 5.11$ & - & 0.44 \\
\hline & \multirow{2}{*}{ Number } & 3 or Less & 235 & 217 & 18 & 7.66 & 0.76 \\
\hline & & More than 3 & 15 & 13 & 2 & 13.33 & - \\
\hline & \multirow{2}{*}{ Laterality } & Right & 117 & 105 & 12 & 10.26 & 0.30 \\
\hline & & Left & 133 & 126 & 8 & 6.02 & - \\
\hline
\end{tabular}

procedure was noted one-month post procedure. Continuous variables were described in terms of mean/ median and standard deviation and compared by chisqaure/fishers exact test where appropriate. Categorical variables were described in terms of frequency and percentages and compared by Independent t-test/ Mann Whitney test. Cox proportion algorithm was used and prevalence ratio was reported with their 95\% class interval.

\section{RESULTS}

We included 250 participants undergoing ureterorenoscopy for upper urinary tract calculi. Access failure rate in our patients was $8 \%(20 / 250)$. Mean stone size of our patients was $9.12 \pm 4.23$. Baseline parameters of our patients are given in table-I. When patients

\section{DISCUSSION}

The choice of treatment for upper urinary tract calculus is dependent on many factors including stone size, number, composition and location. In view of the wider availability and acceptance of ureterorenoscopy as a diagnostic and therapeutic treatment ${ }^{14}$, URS has become the workhouse for most upper urinary tract stones. URS is now commonly done in both pediatric as well as adult population ${ }^{15,16}$. Success of URS is dependent on successful cannulation of the ureteric orifice and accessing the ureter to the level of the stone. This is dependent on many patients and ureter related factors but also on the expertise of the operating surgeon and the availability of a well-equipped endourology suite. 
In the earlier era URS was preceded by metallic/ balloon dilatation. Currently the use of access sheath in flexible ureterorenoscopy as well as development of miniaturized equipment has resulted in rapid advancements as a urological procedure during the past few decades. Not only the size but also the maneuverability has also been improved and developed as flexible ureterorenoscope ${ }^{6}$. Ureterorenoscope is clearly superior to SWL and PNL for upper ureteric stones in some situations e.g. patients with bleeding disorders or continued antithrombotic therapy ${ }^{9}$.

Table-II: Univariate and multivariate analysis.

\begin{tabular}{l|c|c|c}
\hline \multirow{2}{*}{ Age } & \multicolumn{3}{|c}{ Univariate Analysis } \\
\cline { 2 - 4 } & Estimate & Standard Error & $p$-value \\
\hline Gender & 0.976 & $0.943-1.009$ & 0.156 \\
\hline BMI & 0.91 & $0.331-2.51$ & 0.856 \\
\hline Side & 1.06 & $0.969-1.159$ & 0.205 \\
\hline Size & 0.76 & $0.486-1.188$ & 0.228 \\
\hline Location & 1.043 & $0.951-1.145$ & 0.370 \\
\hline Number & 0.146 & $0.043-0.497$ & 0.002 \\
\hline Passage & 1.09 & $0.253-4.696$ & 0.908 \\
\hline Prior URS & 5.05 & $0.334-76.345$ & 0.243 \\
\hline Prior Dj & 4.79 & $1.47-155.62$ & 0.378 \\
\hline Prior intervention & 0.784 & $0.378-1.629$ & 0.515 \\
\hline & 1.044 & $0.503-2.167$ & 0.908 \\
\hline Age & 0.970 & $0.935-1.005$ & 0.096 \\
\hline Location & 6.612 & $1.919-22.780$ & 0.003 \\
\hline Stone Passage & 845.315 & $0.000-1.540 \mathrm{e} 181$ & 0.974 \\
\hline Side & 0.811 & $0.517-1.271$ & 0.360 \\
\hline Body Mass Index & 1.064 & $0.975-1.160$ & 0.162 \\
\hline
\end{tabular}

In spite of all the advancements urologists often encounter situations in which access tothe desired location is difficult and results in need of staged or ancillary procedure ${ }^{8}$. It is important to know the failure rate of primary ureteroscopy access so that patients canbe appropriately counselled in both emergency and elective settings ${ }^{18}$. In an older study by Jones et al failure rate of $11 \%$ was found with semi rigid URS of 9.5Fr and 11Fr10. Whereas Fuller et al found a failure rate of $7.7 \%$ for accessing the unstented ureter ${ }^{5}$ which is similar to our study $(8 \%)$. Karadag et al included all patients and found higher failure rate of $16 \%{ }^{11}$.

Patient, stone and instrument related factors have been studied to predict access failure. In our study patient related factors including age, gender and BMI were found to be insignificant to predict access failure. Most of the patients with history of previous endoscopic intervention (URS/double J stenting) had no difficulty in accessing stone and none of the patients with previous stone passage had access failure ${ }^{12-15}$. However none of these patient related factors were statistically significant predictors on univariate. or multivariate regression analysis. This is explained by small number of patients available for subgroup analysis.

Among the stone-related factors number, size and laterality were found to have no statistical significance for access. However more proximal location was associated with higher failure rate ${ }^{17}$. We found that access failure rate of $15.04 \%$ for proximal stones as compared to $2.19 \%$ for distal stones. Fuller et al also found a higher access failure rate in proximal ureteric stones $(15.45 \%)$. Similar to our study they also found stone location as the only significant predictor for access failure ${ }^{5}$. Stone size, density or S.T.O.N.E score which is a predictor of stone clearance was not studied ${ }^{16-18}$.

The current work is a single center study and our results are limited by sample size for identifying predictors. However, this data provides important base for confirmation by further studies. We have not looked for some potential predictors like mode of admission (emergency vs elective), ureteric dilatation by metallic/balloon dilators before retrograde access or ureteric diameter on contrast study like retrograde pyelography or contrast enhanced CT scan.

\section{CONCLUSION}

Access failure is a fairly common problem during ureterorenoscopy. Proximal ureteric and renal stones are more likely to need staged procedure. Whereas patients with prior history of stone passage or endoscopy are less likely to have access failure. This study provides information that will help urologists to counsel their patients preoperatively regarding their likelihood of failing primary URS, necessitating a second procedure or presenting electively.

\section{CONFLICT OF INTEREST}

This study has no conflict of interest to be declared by any author.

\section{REFERENCES}

1. Ather MH, Paryani J, Memon A, Sulaiman MN. A 10-year experience of managing ureteric calculi: changing trends towards endourological intervention--is there a role for open surgery? BJU Int 2001; 88(3): 173-77.

2. Young H, McKay R. Congenital valvular obstruction of the prostatic urethra. Surg Gynecol Obstet 1929; 48: 509-12.

3. Huffman JL, Bagley DH, Lyon ES. Extending cystoscopic techniques into the ureter and renal pelvis. Experience with ureteroscopy and pyeloscopy. J Am Med Assoc 1983; 250: 2002-2005.

4. Busby JE, Low RK. Ureteroscopic treatment of renal calculi. Urol Clin North Am 2004; 31: 89-98.

5. Ather MH, Nazim SM, Sulaiman MN. Efficacy of semirigid ureteroscopy with pneumatic lithotripsy for ureteral stone surface area of greater than 30mm2. J Endourol 2009; 23(4): 619-22. 
6. Süer E, Gülpinar Ö, Özcan C, Göğüş Ç, Kerimov S, Şafak M. Predictive factors for flexible ureterorenoscopy requirement after rigid ureterorenoscopy in cases with renal pelvic stones sized 1 to $2 \mathrm{~cm}$. Korean J Urol 2015; 56(2): 138-43.

7. Fuller TW, Rycyna KJ, Ayyash OM, Ferroni MC, Mitchell CR, Ohmann E, et al. Defining the rate of primary ureteroscopic failure in unstented patients: a multi-institutional study. J Endourol 2016; 30(9): 970-74.

8. Schoenthaler M, Buchholz N, Farin E, Ather H, Bach C, Bach T, et al. The Post-Ureteroscopic lesion scale (PULS): a multicenter video-based evaluation of inter-rater reliability. World J Urol 2014; 32(4): 1033-40.

9. Elkoushy MA, Violette PD, Andonian S. Ureteroscopy in patients with coagulopathies is associated with lower stone-free rate and increased risk of clinically significant hematuria. International Braz J Urol 2012; 38(2): 195-203.

10. Jones BJ, Ryan PC, Lyons O, Grainger R, McDermott TE, Butler MR. Use of the double pigtail stent in stone retrieval following unsuccessful ureteroscopy. Br J Urol 1990; 66(3): 254-56.

11. Karadag MA, Demir A, Cecen K, Bagcioglu M, Kocaaslan R. Flexible ureterorenoscopy versus semirigid uretero-scopy for the treatment of proximal ureteral stones: a retros-pective compara- tive analysis of 124 patients. Urol J 2014; 11(05): 1867-72.

12. Younis MA, Khan N, Ather MH. To determine the frequency of stone free rates in patients undergoing ureterorenoscopy using STONE score. Eur Urol Suppl 2017; 16(3): e571.

13. Molina WR, Kim FJ, Spendlove J, Pompeo AS, Sillau S, Sehrt DE. The stone score: a new assessment tool to predict stone free rates in ureteroscopy from pre-operative radiological features. Intl Braz J Urol 2014; 40(1): 23-911.

14. Wu CF, Shee JJ, Lin WY, Lin CL, Chen CS. Comparison between extracorporeal shock wave lithotripsy and semirigid ureterorenoscope with holmium: YAG laser lithotripsy for treating large proximal ureteral stones. J Urol 2004; 172(5): 1899-902.

15. Tan AH, Al-Omar M, Denstedt JD, Razvi H. Ureteroscopy for pediatric urolithiasis: an evolving first-line therapy. Urol 2005; 65(1): 153-56.

16. Jing DS, Chang DH, Wang YM. Application of ureteroscopy in peadiatric urology. China J Endoscopy 2007; 13(4): 421-23.

17. Bader MJ, Eisner B, Porpiglia F, Preminger GM. Contemporary management of ureteral stones. Eur Urol 2012; 61(4): 764-72.

18. Matani YS, Al-Ghazo MA, Al-Azab RS, Hani OB, Ghalayini IF, Hani IB. Emergency versus elective ureteroscopic treatment of ureteral stones. Can Urol Assoc J 2013; 7(7-8): e470. 